\title{
Academic Advising Tips for New Educators
}

\author{
Michael L. Mavrovouniotis \\ Northwestern University (Evanston, IL)
}

\section{Introduction}

Have you ever had students who seemed to be in the wrong class or even the wrong major given their talents and desires? Or perhaps students who did not even understand their talents and goals - let alone how a particular class might fit them? The goal of the academic advisor is to avoid these counterproductive situations, by helping the student navigate the maze of educational options and opportunities. Good academic advising is a pre-requisite classroom learning. Do you plan your own advising approach to guide your advisees and foster their development?

Academic advising is not just a clerkish support service; it is an integral part of the educational process. The advisor's office, with its many systematic student contacts, is a powerful mechanism for helping students realize their full potential. Academic advising has an impact on retention, academic success of students, and the students' career choice process.

Many varied and important duties lay claim to a faculty member's time. Advising does not, and should not, take a substantial time commitment. Advisors should have a sense of caring about the students and the willingness to develop and follow good advising practices. They should reflect on their interactions with students and look for ways to improve them. Advising takes a little longer to do right, but it does not demand an excessive commitment that would infringe on other duties and responsibilities.

\section{The Advising Session}

In routine advising sessions, whether associated with registration or not, the advisor should carry out a comprehensive review of the student's progress and future plans. In each session, the advisor has the opportunity to learn a bit more about the student's talents and goals.

- Ask questions on the advisee's recent work: Which classes did the student like (or dislike) last quarter and why? Were there any unexpected academic difficulties or achievements in recent classes?

- Ask for the student's thoughts on educational plans, such as specialization areas and career paths. Offer guidance on feasibility and good means for achieving the student's goals - such as course choices or internships.

- Encourage the student to get second opinions on major issues. Suggest other faculty, university offices, and information sources. 
- Help the student see the big picture. Clarify the role of each class in the curriculum rather than simply stating that it is a requirement. Point out the connections among classes.

In those cases where the student comes for a special consultation, make sure that you make the student comfortable and explore the problem fully before reaching any decisions. Give the student the opportunity to come up with solutions.

- Show openness, interest, and concentrated attention.

- Ask the student to state the problem. Help focus the problem statement and uncover hidden trouble spots, by asking open-ended probing questions.

- Ask for the student's ideas for solving the problem. Help the student generate alternative solutions. Make a chart of the available options, if they are complicated.

- Discuss the mechanics and implications of each solution and identify conflicts.

- Plan a specific order and time frame for action steps, including referrals to other university resources or offices.

- Plan follow-up by the student and/or the advisor and make a definite appointment for review if necessary.

- Review what has transpired, and restate action steps.

Never rush the advising session. In my own experience, 10 minutes is the bare minimum for any session, no matter how trivial the problem. A simple answer to a student dropping in with a simple question only takes a minute or two, but there are two reasons for taking longer. First, in the interest of cultivating the relationship and ensuring that the student will not hesitate to seek future contact, the advisor should take the time to make the student feel at ease, and inquire about other advising issues or the student's interests. It takes ten minutes to demonstrate your interest in the advisee. Second, it's important for the advisor to explore the origin of the question, and find out whether it is related to other obstacles the student is faced with but has not brought up.

The commonplace use of electronic mail by faculty and students provides an alternative way to answer simple questions without appearing hurried or damaging the advisor-student relationship. If more discussion is warranted, the advisor can respond with an offer for an appointment, which is easily arranged by electronic mail.

Advising sessions dealing with complex issues, such as specialization and career paths, will take much longer than this minimum. They may have to be broken down into a series of meetings. At the end of each meeting, the student should be left with a set of questions to ponder for the next meeting.

In the interest of efficiency, the advisor can schedule particular blocks of time for advising sessions. Some tasks (such as explaining overall curricular requirements) can be done with a group of advisees simultaneously - but individual sessions should not be eliminated. 


\section{Responsibility}

There are limits to an advisor's responsibility to the students and they must learn what these limits are. How intrusive should an advisor be, and who makes the ultimate decisions? At one extreme, one might declare that students are adults who can read the catalog and therefore should make their own academic decisions. The other extreme is to be in constant contact with students about every detail and technicality of every decision they make.

Consider a middle path, trying to motivate the students through encouragement and support, yet leaving the responsibility for taking action to the student. Naturally, lower-division students are less likely to be independent and responsible decision makers, and you may need to be more proactive and leave somewhat less freedom to the students. This is understandable, and you should provide the necessary guidance while gradually pushing the students towards more control and responsibility.

Make sure that the student's perception of the advising process matches yours. For example, students are often extremely reluctant to "take up your valuable time" if they perceive advising only in its prescriptive and clerical side. Such a consideration is not to be downgraded, but if you are interested in offering your assistance in developmental advising, it's important to convey to advisees your willingness to engage in conversation and consultation.

\section{Campus Cultures}

The influence of the culture of institutions and student groups on the educational experience is substantial. Your entire interaction with students improves as you gain familiarity with the culture in which the students are immersed. It is, admittedly, not easy to learn the student-side of the institutional culture, but even a general awareness of student life, customs, and habits is helpful. Simple steps such as reading the student newspapers are a good start. The more familiar you become with their culture, the easier your interactions with students become, giving you a clearer view of their problems.

You might even seek familiarity with specific student groups or activities that your advisees are involved in. If one of your advisees is on the swimming team, make it a point to follow the results of the swimming competitions and find out a little about the grueling training and travel schedule.

\section{Recapping}

The advising process should be treated as an integral educational activity, not just a purely clerical task. Faculty advisors should strive to improve the strategies they follow in encouraging student contact, acting in a teaching and supportive role, allowing the students ultimate decisionmaking and responsibility, and helping the students focus on the greater educational and professional objectives - and the means for accomplishing them.

A final note of caution is in order. Serious problems of a non-academic nature (even if brought about by academic events) occasionally arise, such as severe depression, thoughts of suicide, substance abuse, or acute interpersonal problems among students. If you do not possess the requisite special training and skills to deal with such issues effectively, your well-intentioned attempt to help might even worsen the problem. It is best to refer such problems to trained 
counselors. Make sure that the student receives help; make an appointment on the spot. Afterwards, follow up with the counseling office to make sure that the student kept the counseling appointment, and check with the student periodically so that the student knows someone is concerned. In order to deal with such crises, be aware of all the relevant campus resources before any crisis occurs, and keep a handy list of offices, contact names, and phone numbers.

\section{Bibliography}

[1] Winston, R.B. Jr., Miller, T.K., Ender, S.C., Grites, T.J., and Associates, Developmental Academic Advising: Addressing Students' Educational, Career, and Personal Needs, Jossey-Bass Publishers, San Francisco, 1984.

[2] Winston, R.B. Jr., Ender, S.C., Miller, T.K. (editors)Developmental Approaches to Academic Advising, JosseyBass Inc., San Francisco, 1982.

[3] Kramer, H.C., and Gardner, R.E., Advising by Faculty, National Education Association, Washington, DC, 1977.

[4] Gordon, V.N., Handbook of Academic Advising, Greenwood Press, Westport, Connecticut, 1992.

[5] Kuh, G.D. (editor),Cultural Perspectives in Student Affairs Work, American College Personnel Association, Cincinnati, 1993.

MICHAEL L. MAVROVOUNIOTIS is Associate Professor of Chemical Engineering at Northwestern University. He received his Ph.D. from the Massachusetts Institute of Technology in 1989. His recent teaching has included Process Design, Statistics, and Separations. He is the recipient of the Woody Everett Award of ASEE, two Best Paper awards from Computers and Chemical Engineering, and the Ted Peterson award of AIChE (CAST Division). 